\title{
ANALISIS BULLWHIP EFFECT PADA PERENCANAAN KEBUTUHAN MATERIAL BELT CONVEYOR
}

\author{
Indra Dwi Febryanto \\ Fakultas Teknologi Industri Universitas PGRI Adi Buana Surabaya \\ E-mail : indra@unipasby.ac.id
}

\begin{abstract}
Controlling the supply of raw materials belt conveyor is a very important management function because it is a vital company investment, both in terms of value and future prospects. Well-implemented inventory control management can trigger a company's success in production. In manufacturing companies there is often a delay in the arrival of material arrival due to various things, such as the bullwhip effect between the company with suppliers, companies with distributors or companies with buyers. The focus of this research is to know how big the occurrence of bullwhip effect and how to decrease the bullwhip effect that already happened. From the calculation results obtained a decrease in the value of the bullwhip effect from the original to PU White products 2,786 to 1,524, blue PU products 3,297 to 1,455, and PVC Green 2.025 to 1.5794 .
\end{abstract}

Keywords : Belt Conveyor, Bullwhip Effect, Parameter, Supplier

\section{PENDAHULUAN}

Persaingan dunia industri yang semakin ketat mengharuskan pihak perusahaan untuk selalu dapat meningkatkan produktivitasnya agar dapat selalu bertahan hidup khususnya dalam menghadapi era perdagangan bebas.

Iklim dunia industri yang semakin maju seiring dengan perkembangan ilmu pengetahuan dan teknologi telah menimbulkan persaingan yang ketat diantara perusahaan-perusahaan atau yang sekarang lebih dikenal dengan jaringan supply chain. Berbagai macam cara ditempuh pelaku supply chain agar tetap mampu bertahan, bahkan kalau bisa unggul dari pelaku supply chain yang lain. Diantaranya dengan pengaturan di bidang personalia, keuangan, produksi, pemasaran, dan sebagainya harus ditangani sebaik mungkin. Untuk itu diperlukan cara atau metode yang baik dalam menangani setiap bagian dalam perusahaan.

Pengendalian persediaan bahan baku merupakan fungsi manajerial yang penting agar bahan baku yang tersedia sesuai dengan yang dibutuhkan dan dilaksanakan pada waktu yang tepat. Oleh karena itu antara order dan permintaan di masing-masing jaringan supply chain (hulu sampai hilir) diusahakan dapat seminimal mungkin menghilangkan distorsi informasi yang ada. Distorsi ini terjadi pada data permintaan dimana bagian hulu supply chain tidak mendapatkan informasi permintaan yang sesungguhnya. Distorsi informasi mengakibatkan pola permintaan yang semakin fluktuatif ke arah hulu supply chain. Meningkatnya permintaan dari hilir ke hulu inilah yang dinamakan bullwhip effect.

Selama ini perencanaan kebutuhan material belt conveyor yang dilakukan terjadi ketidaksamaan informasi antara bagian hulu dengan bagian hilir sehingga mengakibatkan penumpukan material di sepanjang struktur supply chain. Oleh karena itu fokus penelitian ini adalah untuk meminimalkan tingkat bullwhip effect yang terjadi sepanjang aliran supply chain yang ada.

\section{KAJIAN LITERATUR}

Bulwhip Effect adalah Suatu fenomena dimana permintaan kepadasupplier memiliki variansi yang besar daripada penjualan yang dilakukankepada buyer dan terjadi distorsi kepada level Suppy Chain yang lebih tinggi (Noviani dan Arkho, 2017).Definisi bullwhip effect yang lain menurut Susilo dan Kristyanto (2017) adalah Kelemahan pada aliran informasi sering menimbulkan penyimpangan salah satunya berupa penyimpangan yang jauh antara persediaan yang ada dengan permintaan atau yangdinamakan 
dengan fenomena bullwhip effect. Sedangkan menurut Simchi Levi (2000), bullwhip effect adalah peningkatan variability dari level bawah menuju level atas dan dalam suatu network supply chain. Jadi dapat ditarik kesimpulan bahwa bullwhip effect adalah peningkatan variabilitas permintaan yang terjadi pada setiap level supply chain sebagai akibat adanya distorsi informasi.

Mengapa hal ini bisa terjadi? Menurut Lee et al (1997) ada beberapa penyebab antara lain: ramalan permintaan yang up date, order batching, fluktuasi harga, rationing dan shortage gaming. Simchi-Levi (2000) menyoroti (pesanan dan pengiriman)lead time sebagai salah satu faktor utama yang berkontribusi terhadappeningkatan variabilitas di supply chain.Penyebab terjadinya bullwhip effect menurut Susilo (2008) antara lain: Kebijakan pemesanan yang tidak jelas menyebabkan order batching terjadi sehingga tidak ada aturan yang jelas untuk hal ini, tidak ada data permintaan untuk memisahkan efek fluktuasi harga dan shortage gaming akan memerlukan data permintaan dibandingkan dengan sales, dan tidak ada mengenai shortage atau kekurangan.

Pujawan (2010) mengemukakan beberapa cara mengurangi bullwhip effect antara lain: information sharing, memperpendek atau mengubah struktur supply chain, pengurangan ongkos-ongkos tetap, menciptakan stabilitas harga, dan pemendekan lead time.

\section{METODE PENELITIAN}

Mengacu pada judul penelitian, maka tujuan penelitian yang ingin dicapai adalah meminimalkan tingkat bullwhip effect yang terjadi di sepanjang aliran supply chain yang ada. Perhitungan bullwhip effect yang dilakukan mengacu pada Asmono (2012) menggunakan data order dan permintaan. Analisis menggunakan program Microsoft Excel. Perhitungan bullwhip effect menggunakan rumus sebagai berikut:

$$
\text { Bullwhip effect }=\frac{\text { CVOrder }}{\text { CV Permintaar }}(1)
$$

Dimana:

\section{Order $=$ Koefisien Variansi Order}

$\mathrm{CV}$ Permintaan $=$ Koefisien Variansi
Permintaan

Koefisien Variansi dihitung dengan rumus sebagai berikut:

Koefisien Variansi $=\frac{a}{F}=\frac{\text { simpangan bakudate }}{\text { rata-rata data }}$
Sari et al (2013) menentukan usulan perbaikan order dan demand produk LLSR.Penelitian ini dimulai dengan menghitung bullwhip effect pada dua eselon. Metode yang digunakandalam peneleitian ini adalah Metode simulasi diskrit. Hasil penelitian ini yaitu Nilai bullwhip effect pada eselon 1 (supplier dan PPIC) $=1.22$ dan eselon 2 (PPIC dan distributor $)=0.78$. Nilai tersebut menunjukan terjadinya bullwhip effect pada eselon 1 sedang eselon 2 tidak terjadi. Suseno dan Ikatrinasari (2015) Penelitian ini menghitung dan menentukan rencana penjualan dengan menggunakan empat metode peramalan eksponensial. Selanjutnya, dilakukan perencanaan persediaan dengan metode DRP untuk menghasilkan kapan dan berapa banyak barang yang didistribusi ke cabang penjualan dengan biaya terendah. Penelitian ini juga membahas hasil perhitungan bullwhip effect selama 3 bulan.

Hasil penelitian menunjukkan bahwa dengan menerapkan DRP dapat menurunkan nilai bullwhip effect baik untuk cabang Jakartadan Solo. Susilo dan Kristyanto (2017) Pengukuran dan analisa yang dilakukan di Toko Holi berupaya untuk mencari tahu seberapa besar bullwhip effect yang terjadi dan selanjutnya mencari alternatif dan solusi untuk mengurangi terjadinya bullwhip effect pada supply chain dengan menggunakan metode periodic review system dan menentukan safety stock yang optimal.

Sebuah bisnis dikatakan mengalami bullwhip effect jika variansi produksinya lebih besar daipada variansi permintaannya atau dengan kata lain amplifikasinya lebih besar dari 1. Rasio amplifikasinya dihitung menggunakan persamaan berikut ini

$$
\text { Rasio amplifikasi }=\frac{V \text { Order }}{V \text { Permintaar }}
$$

Dimana:

V Order $=$ Variansi order

V Permintaan $=$ Variansi permintaan

Berikut ini adalah keterangan dari persamaan yang digunakan

1. Jika rasio amplifikasi sama dengan satu, maka tidak terjadi bullwhip effect dan berarti besarnya produksi sama dengan permintaan aktual.

2. Jika rasio amplifikasi lebih besar dari satu, maka ini menunjukkan terjadi bullwhip effect. 3. Jika rasio amplifikasi lebih kecil dari satu, artinya belum mampu memenuhi permintaan secara total. 
Ketika nilai bullwhip effect yang terjadi adalah lebih dari 1 maka dilakukan langkah berikutnya yaitu dengan melakukan simulasi salah satu standar deviasi pada tiap eselon (bagian

\section{HASIL DAN PEMBAHASAN}

order atau demand) dengan rata-rata demand dan order adalah tetap. Simulasi akan berhenti ketika nilai bullwhip effect sama dengan 1.

Tabel 1. Data-Data Produksi

\begin{tabular}{lllllll}
\hline & \multicolumn{2}{c}{ PU PUTIH } & \multicolumn{3}{c}{ PU BIRU } & \multicolumn{2}{c}{ PVC HIJAU } \\
& ORDER & PERMINTAAN & ORDER & PERMINTAAN & ORDER & PERMINTAAN \\
\hline $\mathbf{1}$ & 24500 & 23138 & 17600 & 11970 & 22100 & 18835 \\
$\mathbf{2}$ & 0 & 20824 & 0 & 10773 & 22100 & 16951 \\
$\mathbf{3}$ & 24500 & 18741 & 17600 & 9696 & 0 & 15256 \\
$\mathbf{4}$ & 24500 & 16867 & 0 & 8726 & 22100 & 13730 \\
$\mathbf{5}$ & 0 & 15181 & 17600 & 7854 & 22100 & 12357 \\
$\mathbf{6}$ & 24500 & 13662 & 0 & 7068 & 0 & 0 \\
$\mathbf{7}$ & 0 & 12296 & 17600 & 6362 & 22100 & 10010 \\
$\mathbf{8}$ & 24500 & 11067 & 0 & 5725 & 0 & 9009 \\
$\mathbf{9}$ & 0 & 9960 & 0 & 5153 & 0 & 8108 \\
$\mathbf{1 0}$ & 24500 & 8964 & 17600 & 4638 & 22100 & 7297 \\
$\mathbf{1 1}$ & 0 & 8068 & 0 & 4174 & 0 & 6567 \\
$\mathbf{1 2}$ & 0 & 7261 & 0 & 3756 & 0 & 5911 \\
\hline
\end{tabular}

Sumber: Hasil Analisis Data, 2018

Berdasarkan data yang diperoleh dari Tabel 1 maka pada tahapan berikutnya adalah data tersebut diolah sesuai dengan kebutuhan akan tujuan dari penelitian ini. Dengan mengolah datadata tersebut untuk mengetahui apakah permintaan pada periode selanjutnya dapat optimal sesuai dengan kemampuan dari produksi dan supply. Dalam hal ini, kita dapat mengukur nilai amplifikasi atau lonjakan permintaan pada masing-masing produk, yaitu dengan menghitung rata-rata penjualan dan permintaan, menghitung standar deviasi penjualan dan permintaan, menghitung koefisien variabilitas $(\mathrm{CV})$ penjualan dan permintaan selanutnya menghitung nilai Bullwhip Effect yaitu membagi koefisien variabilitas (CV) permintaan dengan koefisien variabilitas (CV) penjualan. Adapun beberapa rumus yang digunakan dalam Microsoft office excel 2007 adalah sebagai berikut :

Tabel 2 Perhitungan Formulasi Dalam Microsoft Office Excel 2007

\begin{tabular}{|c|c|c|}
\hline NO & NAMA & FORMULA \\
\hline 1 & Rata-rata & $\operatorname{AVERAGE~}(\ldots)$ \\
\hline 2 & Standar Deviasi & $\operatorname{STDEV}(\ldots)$ \\
\hline 3 & Coefisien variabilitas order & STDV /Rata-rata \\
\hline 4 & $\begin{array}{c}\text { Coefisien variabilitas } \\
\text { Permintaan }\end{array}$ & STDV /Rata-rata \\
\hline 5 & Bullwhip effect & CV Permintaan / CV Penjualan \\
\hline 6 & Parameter Bullwhip effect & $\begin{array}{c}\text { Lead time } 90 \text { hari dan pengamatan } 12 \\
\text { bulan atau } 360 \text { maka } \\
2 x L\end{array}$ \\
\hline 7 & Keterangan & $\begin{array}{c}\text { And (no } 5<=\text { no } 6 \text { ) Ketika terjadi } \\
\text { Bullwhip Effect secara otomatis nilai } \\
\text { akan false dan jika tidak akan true }\end{array}$ \\
\hline
\end{tabular}

Sumber: Asmono, 2012 
Hasil dari pengolahan data dapat dilihat pada tabel 3 di bawah ini

Tabel 3 Pengolahan Data Menggunakan Ms.Excel

\begin{tabular}{lllllllll}
\hline Produk & Data & Total & Rata-rata & STDV & CV & BE & Parameter & Keterangan \\
\hline PU & Order & 147000 & 12250 & 12794,71 & 1,044 & 2,786 & 1,625 & False \\
Putih & & & & & & & & \\
& Permintaan & 166029 & 13835,75 & 5185,152 & 0,374 & & & \\
PU & Order & 88000 & 7333,33 & 9062,744 & 1,235 & 3,297 & 1,625 & False \\
Biru & & & & & & & & \\
& Permintaan & 85895 & 7157,91 & 2682,461 & 0,374 & & & \\
PVC & Order & 132600 & 11050 & 11541,35 & 1,044 & 2,025 & 1,625 & False \\
Hijau & & & & & & & & \\
& Permintaan & 124031 & 10335,92 & 5329,906 & 0,515 & & & \\
\hline
\end{tabular}

Sumber: Hasil Analisis Data, 2018

Berdasarkan perhitungan tabel 3 dapat dilihat bahwa semua produk yang ada (PU Putih, PU Biru, dan PVC Hijau) memiliki nilai BE > 1, hal ini berarti bullwhip effect terjadi sehingga perlu dilakukan langkah perbaikan. Langkah perbaikan yang ditempuh yaitu:

- Memberikan usulan perbaikan BE dengan cara mensimulasikan salah satu standar deviasi pada tiap eselon (bagian order atau demand) dengan rata-rata demand dan order adalah tetap. Setelah didapatkan standar deviasi di bawah parameter dalam Tabel 3, maka simulasi stop dan nilai terakhir itulah yang digunakan.

Tabel 4 Pengolahan Data Menggunakan Ms.Excel

\begin{tabular}{lllllllll}
\hline Produk & Data & Total & Rata-rata & STDV & CV & BE & Parameter & Keterangan \\
\hline PU & Order & 147000 & 12250 & 7000 & 0,571 & 1,524 & 1,625 & True \\
Putih & & & & & & & & \\
& Permintaan & 166029 & 13835,75 & 5185,152 & 0,374 & & & \\
PU & Order & 88000 & 7333,33 & 4000 & 0,545 & 1,455 & 1,625 & True \\
Biru & & & & & & & & \\
& Permintaan & 85895 & 7157,91 & 2682,461 & 0,374 & & & \\
PVC & Order & 132600 & 11050 & 9000 & 0,814 & 1,579 & 1,625 & True \\
Hijau & & & & & & & & \\
& Permintaan & 124031 & 10335,92 & 5329,906 & 0,515 & & & \\
\hline
\end{tabular}

Sumber: Hasil Analisis Data, 2018

\section{KESIMPULAN}

Berdasarkan hasil analisis dan pembahasan dapat ditarik kesimpulan mengenai bullwhip effect perencanaan kebutuhan material belt conveyor adalah sebagai berikut:

1. Secara perhitungan untuk perencanaan kebutuhan material belt conveyor dari 3 produk yang diteliti yaitu PU putih, PU biru, dan PVC hijau ketiga-tiganya menghasilkan nilai Bulwhip Effect (BE) diatas paramater antara lain: 2,786;3,297;2,025.
2. Setelah dilakukan simulasi untuk nilai standar deviasi order maka didapatkan nilai baru yaitu 7000 untuk produk PU putih, 4000 untuk PU biru, dan 9000 untuk PVC hijau.

3. Ketiga nilai diatas adalah nilai optimal dari masing-masing produk yang diteliti karena berada dibawah paramater Bullwhip Effect yang digunakan. 


\section{DAFTAR PUSTAKA}

Asmono, F., T., 2012. Analisa Bullwhip Effect Pada Retail Air Minum Dalam Kemasan Studi Kasus Pada CV. Tirta Mekar Jaya. Universitas Muhammadiyah Surakarta

Carlsson, C.,dan Fuller, R.,1999, Soft Computing and the BullwhipEffect, Economic \& Complexity, Vol 2,pp.126.

Lee H. L.,Padmanabhan V., Whang S. 1997. The Bullwhip Effect In Supply Chain. Pensylvania State University, SloanManagement Review Volume 38(3),pp93-102

Levi., D., S., 2000, Designing And Managing The Supply Chain, Mc Graw - Hill Companies Inc, United States of America.

Noviana dan Arkho, A., 2017.Analisis Pengendalian Persediaan Barang Guna Mengurangi Bullwhip Effect Pada Supply Chain Cv. Yan Utama Corporation Pasuruan. Jurnal Teknik 6. Vol.1

Pujawan., I., P., dan Mahendrawati, E.R., 2010, Supply Chain Management, Edisi Kedua, PT. Guna widya, Surabaya.

Sari, R., Ilhami, M., A., Kurniawan, B., 2013. Analisis Bullwhip Effect dalam Sistem Rantai Pasok pada Produk LLSR. Jurnal Teknik Industri, Vol.1, No.4, pp.341-346

Susilo, C., B., R., dan Kristyanto, B., 2017. Analisa Bullwhip Effect Dengan Metode Periodic Review. Prosiding Seminar Nasional UNISBANK ke-3

Suseno, L., dan Ikatrinasari, Z., F., 2015. Analisis Bullwhip Effect Terhadap Penerapan Distribution Resource Planning Di Pt. Mnj. Jurnal Teknik Industri, Vol. X, No. 3.

Susilo, Tri. 2008. Analisa Bullwhip Effect pada Supply Chain. Surabaya: Jurnal Penelitian Ilmu-Ilmu Teknik, 8 (2). pp. 64-73. 